\title{
Endurance training slows breast tumor growth in mice by suppressing Treg cells recruitment to tumors
}

\author{
Amit Hagar ${ }^{1,2,3^{*}} \mathbb{D}$, Zemin Wang ${ }^{3}$, Sachiko Koyama ${ }^{4}$, Josua Aponte Serrano ${ }^{2}$, Luma Melo ${ }^{1,3}$, Stephanie Vargas ${ }^{1}$, \\ Richard Carpenter ${ }^{4,5}$ and John Foley ${ }^{4,6}$
}

\begin{abstract}
Background: Aerobic exercise has been shown to slow tumor progression in rodents and humans, but the mechanisms behind this effect are still unclear. Here we show that aerobic exercise in the form of chronic endurance training suppresses tumor recruitment of $\mathrm{FoxP}^{+}$Treg cells thus enhancing antitumor immune efficiency.
\end{abstract}

Methods: Adult wild-type and athymic BALB/c female mice were endurance-trained for 8 weeks. Circulating leukocytes as well as muscle and liver mtDNA copy number were compared to aged-matched concurrent sedentary controls to establish systemic effects. 4T1 murine mammary tumor cells were injected subcutaneously to the 4th mammary pad at the end of the training period. Tumor growth and survival rates were compared, together with antitumor immune response.

Results: Exercised wild-type had 17\% slower growth rate, 24\% longer survival, and 2-fold tumor-CD ${ }^{+}$8/FoxP3 ${ }^{+}$ratio than sedentary controls. Exercised athymic BALB/C females showed no difference in tumor growth or survival rates when compared to sedentary controls.

Conclusions: Cytotoxic T cells are a significant factor in endurance exercise-induced suppression of tumor growth. Endurance exercise enhances antitumor immune efficacy by increasing intratumoral $\mathrm{CD} 8^{+} / \mathrm{FoxP}^{+}{ }^{+}$ratio.

Keywords: Endurance exercise, Forced running wheels, Treg cells, $\mathrm{CD}^{+} / \mathrm{FoxP}^{+}$ratio, Solid tumor progression, Murine mammary tumor, Hypoxia

\section{Background}

Aerobic exercise has been known to systemically alter many physiological features in humans [1] and is currently considered a part of "standard of care" approaches to the prevention of many common chronic conditions [2]. The mechanisms that underlie its effect on the progression of disease, however, are harder to assess given the obvious limitations on adherence of patients to structured physical exercise and the difficulty of obtaining dose-response data in the critically ill. To circumvent this limitation in human patients, rodent exercise

\footnotetext{
* Correspondence: hagara@indiana.edu

'History \& Philosophy of Science \& Medicine Department, Indiana University, Morrison Hall 314, Bloomington, IN 47405, USA

${ }^{2}$ Intelligent Systems Engineering Department, Indiana University,

Bloomington, IN, USA

Full list of author information is available at the end of the article
}

models have been developed with the two most prevalent being the voluntary running wheel [3] and the electric-shock treadmill [4].

Both these models, however, are suboptimal for the purpose of mechanistic evaluation of dose-response effects in human disease models. While the voluntary running wheel does not force the exercise on the animals, unless proper monitoring technology is deployed it requires stress-inducing single-caging so that individual dose recordings can be made for each animal. The problem here is that since the running is voluntary, the dose is not controllable, and varies widely between animals. In addition, given mice behavioral patterns, the type of aerobic exercise this model simulates is closer to high intensity interval training (HIIT) rather than to chronic endurance exercise (CEE) [5]. Both HIIT and CEE have

(c) The Author(s). 2019 Open Access This article is distributed under the terms of the Creative Commons Attribution 4.0 International License (http://creativecommons.org/licenses/by/4.0/), which permits unrestricted use, distribution, and reproduction in any medium, provided you give appropriate credit to the original author(s) and the source, provide a link to the Creative Commons license, and indicate if changes were made. The Creative Commons Public Domain Dedication waiver (http://creativecommons.org/publicdomain/zero/1.0/) applies to the data made available in this article, unless otherwise stated. 
similar results on improving aerobic fitness [6], but untrained humans prefer to pursue the latter rather than the former, as it is easier to implement on a regular continuous basis [7]. In addition, mice perform voluntary running in dosage that no human, even elite athletes, can mimic with HIIT, which limits the human relevance of the voluntary wheel model. The other prevalent model, the electric-shock treadmill, can be used to induce CEE and allows group caging, but is based on forcing an unmotivated animal to continue exercising with an electric shock grid. Therefore, it may incur additional physical stress that may mask desired health effects. As a result, only a small fraction of exercise rodent models mimic controllable and quantifiable aerobic exercise in dosages that are relevant to human disease [8].

Based on epidemiologic evidence and randomized exercise intervention trials on the association between physical activity and breast cancer risk [9], the role of physical activity in breast cancer prevention is widely acknowledged today. Studies show average reduction in breast cancer risk in physically active women, with the strongest associations found for recreational and household activities and for activity that was of at least moderate intensity and sustained over a lifetime [10]. More recently, a pilot study in post-menopausal women detected a correlation between tumor progression rates of early stage invasive ductal carcinoma and the aerobic fitness levels of the hosts: the more aerobically fit is the patient, the longer is her estimated tumor doubling time [11]. Motivated by this phenomenon, the purpose of the pilot study presented here was to investigate potential mechanisms behind it in mice.

The well-known systemic effects of aerobic exercise on the immune system [12] form a natural basis for this investigation. The intricate relations between solid tumors and the immune system have been a subject of ongoing research [13], with a recent rise in interest due to the rediscovery of the immunotherapeutic paradigm [14]. Cytotoxic T cells are an effective tool in the host's battle against solid tumors, but since the late 1970s it was suggested that T cells are also capable of suppressing the rejection of implanted tumors [15]. Two decades later it was demonstrated that $\mathrm{CD} 4^{+} \mathrm{FoxP3}^{+} \mathrm{T}-$ cells, termed "regulatory," or Tregs, were responsible for the induction of dominant immune tolerance to tumors [16]. Their ability to inhibit antitumor response, quantified by the intratumoral ratio between $\mathrm{CD}^{+}$cytotoxic $\mathrm{T}$ cells and FoxP3 ${ }^{+}$Treg cells, has been shown to be a marker for antitumor immunity [17]. A relatively high number of FoxP3 ${ }^{+}$ Treg cells, resulting in a decreased $\mathrm{CD}^{+} / \mathrm{FoxP}^{+}$ratio, is also significantly associated with shorter overall survival in the majority of solid tumors investigated, including breast cancer [18-20].

In this pilot study we introduce a controllable and quantifiable rodent model for aerobic exercise as an alternative to the standard treadmill or the voluntary running wheel that avoids single caging or electrical shock. We also suggest a low-stress CEE training protocol with which we identify a minimal dosage of endurance training sufficient for inducing systemic changes in circulating leukocytes and markers for mitochondrial function. Applying this exercise model to a murine mammary tumor, we were able to detect a significant suppression of tumor growth in animals that underwent endurance training compared to sedentary mice. We further found that tumor growth suppression was lost in $\mathrm{T}$ cell-deficient mice suggesting the effects on immune function are a significant factor in exercise-induced suppression of tumors.

\section{Methods}

\section{Running wheel apparatus}

The model is based on two parts, a set of forced running wheels and a controllable moving belt on which they can be mounted (Additional file 1: Figure S1). This apparatus houses 4 mice, one per wheel, and in principle can be used to control and quantify endurance training for an individual mouse. For the pilot experiment detailed below, we used 3 apparatuses and calibrated their digital controllers so that training of 12 mice can be performed simultaneously at the same running speed.

\section{Animals}

The training protocol conformed to the standards of humane animal care and was approved by the Indiana University Bloomington IACUC. Twenty-four 10-week-old $\mathrm{BALB} / \mathrm{c}$ female mice and sixteen age-matched Foxn1-/nude (athymic) BALB/c female mice (Charles River Laboratory) were housed four per cage in a $12 \mathrm{~h} / 12 \mathrm{~h}$ light/ dark cycle, with mean temperature of $23 \pm 2{ }^{\circ} \mathrm{C}$ and relative humidity of $55 \pm 10 \%$. Mice were divided randomly to two groups, Exercised (Ex) and Sedentary (Sed). Mice were fed standard chow and water ad libitum, and their individual weight and mean daily food intake were monitored once a week by measuring cage food weight in two consecutive days, ignoring nibbling waste in the bedding. Before sample collection, mice were initially anesthetized by $2 \%$ isoflurane supplied by a vaporizer and exsanguinated with a cardiac left ventricle stick. Death was confirmed by cervical dislocation.

\section{Training protocol}

In the training period mice exercised 5 days a week, for 8 consecutive weeks. Prior to this period, in the first 2 weeks, mice were acclimatized to the running apparatus, spending $5 \mathrm{~min}$ inside the wheels without running in week 1 , and then $8 \mathrm{~min}$ with minimum velocity $(2 \mathrm{~m} /$ min) in week 2 . From the 1 st week of the training period onwards they increasingly spent more time running, 
starting at minimum velocity and increasing it in the last 2 min of the run to the maximum velocity of that week. This maximum velocity increased throughout the training period. (Additional file 1: Figure S2).

To avoid stress, we trained the mice with no a-priori goal. Instead, we implemented the following rule: when a mouse would show first signs of exhaustion by freezing or clinging to the rungs, the velocity would be lowered until the mouse would begin running again. This rule ensured the mice kept running continuously for longer and longer periods with slowly increasing velocities, adjusting the intensity level to the ability of the lowest performing mouse. In the 8th and final week the mice ran for $26 \mathrm{~min}$ a day, spending $1 \mathrm{~min}$ at $6 \mathrm{~m} / \mathrm{min}, 1 \mathrm{~min}$ at $8 \mathrm{~m} / \mathrm{min}, 22 \mathrm{~min}$ at $10 \mathrm{~m} / \mathrm{min}$, and $2 \mathrm{~min} 12 \mathrm{~m} / \mathrm{min}$.

To eliminate other potential sources of difference between the groups and to isolate training effects as the sole factor for the systemic changes, the sedentary mice were put inside the wheels immediately after the running session has ended for an increasing equivalent time period without the wheel being activated. Feces were collected from cages of both groups before, during, and after the training period to control for cortisol levels.

After training period ended, mice remained in their cages for $72 \mathrm{~h}$ to avoid transient effects. At that point 6 mice were picked randomly, 3 from each group, and were sacrificed. The remaining mice were used for tumor inoculation. No statistical difference in mean weight was detected between each random sample and the respective original group (2-sided t-test $\mathrm{p}_{\mathrm{Ex}}=0.58$ and $\mathrm{p}_{\text {Sed }}=0.49$, respectively).

\section{Lactate kinetics}

To further validate the training protocol, we have repeated it in same-age 6 female Balb/c mice and performed a variation of a lactate threshold test on them immediately after training period has ended. In this experiment blood lactate concentration was measured from a tail-prick using a handheld blood lactate analyzer (Lactate+, Nova Biomedical). Measurements were performed before exercise (base level), immediately after a $5 \mathrm{~min}$ session has ended in the wheel with $8 \mathrm{~m} / \mathrm{min}$ running speed, and then in two relaxation time points $5 \mathrm{~min}$ and $15 \mathrm{~min}$ after the exercise has ended. 6 same-age sedentary Balb/c females were used as control group.

\section{Tumor inoculation and size measurements}

4 T1 murine mammary tumor cell line (ATCC) was used for inoculation. $2 \times 10^{4}$ cells were injected subcutaneously into the 4th mammary pad. 2 out of 9 exercised wild-type BALB/c mice had to be discarded due to injection failure. Tumor volume was measured with a caliper by the same person who was blinded to the study groups. Once tumor volume exceeded $1000 \mathrm{~mm}^{3}$ mice were sacrificed and blood, tumor and tissue were harvested.

\section{qPCR and gene expression}

Hind limb muscles (from the rear right leg) and livers were collected and snap frozen in liquid $\mathrm{N}_{2}$. Total RNA was collected from muscle using an RNA isolation system (Promega). Genomic DNA were collected from muscle and liver tissue using a DNA purification kit (Promega). Total RNA from muscle was subjected to reverse transcription (RT) followed by qPCR with the following primers: Tnni1 (Forward): 5'-CCACGAGGACTAAACTAGGCA-3', Tnni1 (Reverse): 5'-CCTCTCAACTTCCGGCATGG-3'; Tnni2 (Forward): 5'-CCGCCGAGAATCTGAGAAGG-3', Tnni2 (Reverse): 5'-TGCAGAGTTCCTGCACTTCA-3'; ActinB (Forward): 5' -CACTGTCGAGTCGCGTCC-3', ActinB (Reverse): 5'-CGCAGCGATATCGTCATCCA-3'. Muscle and liver mtDNA was subjected to qPCR using the following primers: CoxII (Forward): 5' -GCCGACTAAATCAAGCAACA-3', CoxII (Reverse): 5'-CAATGGGCATAAAGCTATGG-3'; D-loop (Forward): 5'-GGCCCATTAAACTT GGGGGT-3', D-loop (Reverse): 5'-GGCTGATTAGACCCGATACCA-3'; BetaGlobin (Forward): 5'-GAAGCGATTCTAGGGAGCAG-3', BetaGlobin (Reverse): 5'-GAGC AGCGATTCTGAGTAGAGA-3'.

\section{Fecal corticosterone measures}

Thirty fecal pellets were randomly collected from cages of exercised and sedentary mice prior to, and during training at the 1 st, 4th, 7th, and 10th week. Fecal pellets were initially frozen and one day prior to extraction were dried $16 \mathrm{~h}$ at $60{ }^{\circ} \mathrm{C}$ then homogenized extracted in ethyl acetate $(0.1 \mathrm{ml} / .1 \mathrm{~g})$ with vigorous shaking for $30 \mathrm{~min}$. The suspension was spun at $2500 \mathrm{rpm}$ for $30 \mathrm{~min}$ in a swinging bucket rotor in the Allegra 6R centrifuge (Beckman Coulter), the supernate removed, evaporated with a positive pressure manifold (Biotage) and stored at $-20{ }^{\circ} \mathrm{C}$. The reside was dissolved in $100 \mathrm{ul}$ absolute ethanol (Koptec), then two 5ul samples taken, diluted with 4 volumes of $\mathrm{AB}$ buffer from the kit (Corticosterone Elisa, Arbor Assays) and vortexed. Elisa was performed according to kit instructions.

\section{Cell blood counts (CBC)}

Blood was collected into heparinized vials via intracardiac puncture. Whole blood samples were subjected to standard $\mathrm{CBC}$ via ANTECH Diagnostics (Indianapolis) that included white blood cell, neutrophil, lymphocyte, monocyte, and eosinophil counts.

\section{Immunohistochemistry}

Formalin-fixed, paraffin-embedded tumor tissue from the mice tumors were subjected to IHC as previously 
described [21, 22]. The antibodies used included CD8a and FoxP3 (Cell Signaling Technology).

\section{Muscles dissection}

A combination of Soleus and Gastrocnemius muscle fibers were dissected from the right hind limb of each animal.

\section{Statistical analysis}

Data were expressed as mean \pm SE and were compared with commercial SPSS software using two-sided student $\mathrm{t}$-test between independent means and, given the small sample size in some of the tests, a non-parametric mean difference permutation test which has no assumptions of distribution. Survival curves and log rank estimates were obtained with commercial SPSS software. $p<0.05$ was considered statically significant.

\section{Results}

An established low-stress CEE model

8 -weeks training on the model (following a 2-weeks orientation period) significantly increased slow twitch muscles expression, evidenced by increased Tnnil mRNA, but not fast twitch muscles, evidenced by no difference in Tnni2 mRNA (Fig. 1a). This muscle type differential is a known marker for endurance fitness [23, 24]. We concentrated on a combination of soleus and gastrocnemius muscles as they are known to contain both slow and fast twitch fibers. In this pilot study we didn't differentiate between them. Studies are underway to do so in a larger sample of mice. Additionally, we observed decreased mtDNA copy number in the liver (Additional file 1: Figure S3), a known marker for high-intensity endurance fitness level [25-27]. Finally, the lactate kinetics test showed that trained mice had lower levels of blood lactate after a short exercise period, and a quicker clearance rate than sedentary mice (Fig. 1b), a phenomenon that indicates greater aerobic fitness [28]. No significant differences between the exercise and the sedentary groups were detected with respect to food intake (Additional file 1: Figure S4). Lastly, cortisol levels measured from feces taken prior to, during, and at the end of the training period remained stable, and no difference was detected between the exercise

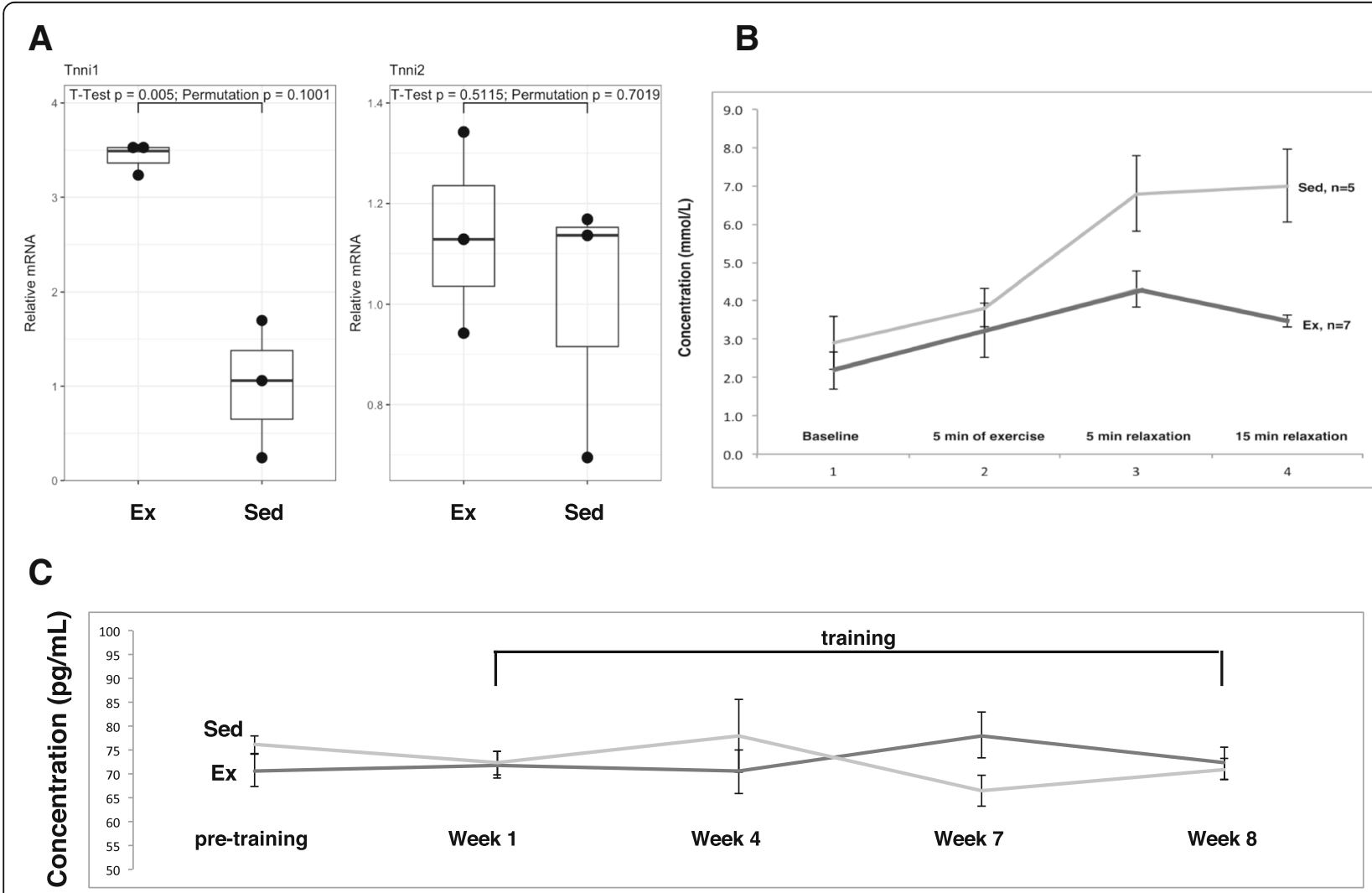

Fig. 1 An established low-stress CEE model. a Effect of 8 weeks endurance training on slow twitch muscles composition. NS = statistically not significant. Data presented as mean \pm SE with $95 \%$ confidence intervals. b Lactate kinetics after short exercise bout. Lactate levels measured in 0.7 $\mu L$ blood drawn from tail with a handheld lactate analyzer (Lactate+ Nova-biomedical) showed faster clearance and lower concentration in endurance trained vs. sedentary adult Balb/c female mice ( $N=6$ in each group). c Mean cortisol levels ( $\mathrm{pg} / \mathrm{mL}$ ) in feces collected from cages before, during and after training period. No significant difference was detected between the means $(n=16, p=0.97)$, as well as between means at the different time points ( $p>0.29$ in all comparisons). Data presented as mean \pm SE with $95 \%$ confidence intervals 
and the sedentary groups (Fig. 1c), suggesting the exercise training program did not induce undue systemic stress on the animals. A systemic decreased level of circulating leukocytes was observed in the WBC differential analysis (Additional file 1: Figure S5). These effects were achieved with a maximal speed of $12 \mathrm{~m} / \mathrm{min}$ at the 8 th week, which is consistent with other reports on the maximal speed a mouse can continuously run without adverse stimuli [29]. The data indicate our novel murine exercise model and training protocol result in known physiological changes associated with vigorous endurance exercise training.

\section{Effect of training on tumor progression rate}

To ascertain the effect of endurance training on early stage tumor growth, BALB/c mice were subjected to either the exercise program described above for 8 weeks or were kept sedentary as described in the Materials and Methods. $72 \mathrm{~h}$ after training had ended $4 \mathrm{~T} 1$ breast cancer cells were implanted in the mammary fat pad of exercised and sedentary mice. Mean tumor size in the exercised mice was significantly smaller than tumors in the sedentary animals throughout the time course of the study (Fig. 2a). The tumors in sedentary mice $(n=9)$ had a mean doubling time of 2.1 days \pm 0.06 whereas the exercised mice $(n=7)$ had a mean doubling time of 2.46 days \pm 0.11 . A statistically significant difference in doubling time between the groups (Fig. 2b) was detected. A Kaplan Meier survival curve showed that exercised mice had a significantly longer survival compared to sedentary mice (Fig. 2c, Log rank $p<$ 0.001). Furthermore, a significant difference was detected in mean survival days with the sedentary group at 21.3 days \pm 0.5 and the exercised group at 25.1 days \pm 1.4 . These data strongly point to a slower tumor growth and an improved outcome for mice that were exercise-trained compared to sedentary mice.

\section{Endurance exercise results in a greater tumor immune response}

In an attempt to understand a potential mechanism by which exercise training could have suppressed tumor growth and enhanced animal survival, the systemic immune response was assessed. Cell blood counts were performed on blood from the animals at the conclusion

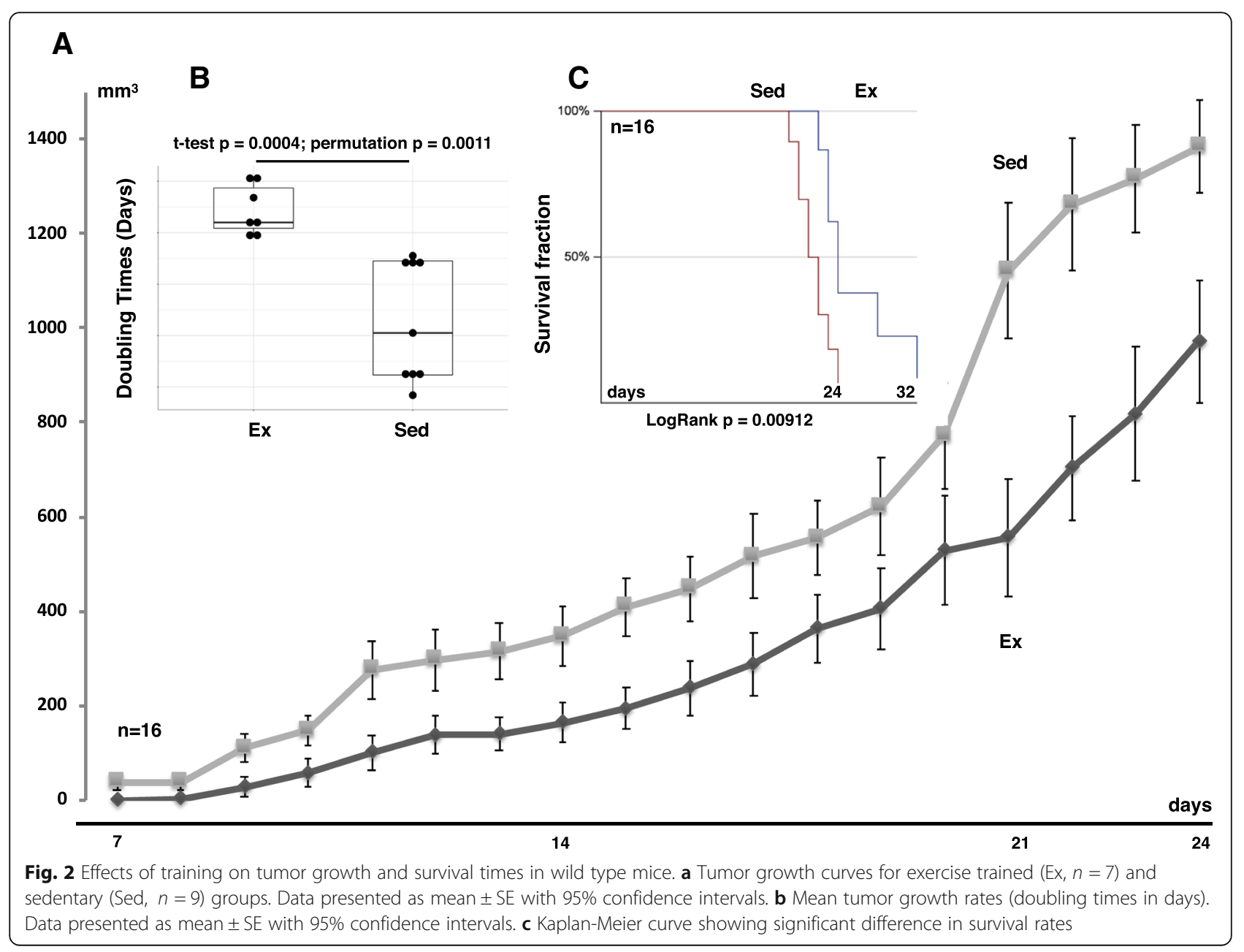


of the study. Absolute counts of circulating leukocytes were observed to be significantly lower in the exercisetrained group prior to tumor inoculation (Additional file 1: Figure S5), a phenomenon consistent with known systemic effects of CEE on the human immune system [30]. However, there was a significantly greater induction of an immune response in the exercised group in response to the presence of the tumor (Fig. 3 \& Additional file 1: Figure S6), also consistent with prior evidence [31]. Total white blood cell count, neutrophils, and monocytes were significantly higher in systemic blood from the exercise-trained mice relative to the sedentary mice (Figs. 3a-c). These data would suggest a possible enhanced antitumor immune response in the exercise-trained mice.

\section{Endurance exercise enhanced antitumor immunity by increasing the intratumoral $\mathrm{CD}^{+} / \mathrm{FoxP3}^{+}$ratio}

To assess whether there was an increased antitumor immune response in the exercised mice, tumors were collected and subjected to IHC for the detection of T cells (Fig. 4a). The presence of $\mathrm{T}$ cells, specifically the intratumoral ratio between $\mathrm{CD}^{+}$cytotoxic $\mathrm{T}$ cells and $\mathrm{FoxP}^{+}$ Treg cells, has been previously shown to be a marker for antitumor immunity [15]. Furthermore, a relatively high number of $\mathrm{FoxP}^{+}$Treg cells, resulting in a decreased $\mathrm{CD}^{+} 8 / \mathrm{FoxP}^{+}$ratio, is also strongly associated with poor prognosis in breast cancer patients [18-20]. Interestingly, significantly lower levels of $\mathrm{FoxP}^{+}{ }^{+}$Tregs were observed in the tumors from exercised mice compared to sedentary tumors (Fig. 3b). No difference in $\mathrm{CD} 8^{+} \mathrm{T}$ cells were observed in the tumors from exercised and sedentary mice (Fig. 3c). However, the change in Fox $3^{+}$cells resulted in a significantly higher $\mathrm{CD}^{+} / \mathrm{FoxP}^{+}$ratio in exercise trained animals (Fig. 3d). The data suggest exercised animals have a greater antitumor immunity that could account for the observed suppression of tumor growth and enhanced survival.

\section{No effect on tumor growth in immune deficient athymic mice}

These results suggest that antitumor immunity, and specifically $\mathrm{T}$ cells, are strongly associated with the exercisemediated suppression of tumor growth. To directly assess this hypothesis, we performed the same endurance training program and tumor growth study with $4 \mathrm{~T} 1$ cells on immunodeficient athymic BALB/c mice that do not have mature $\mathrm{T}$ cells (Foxn1-/- nude BALB/c, Charles River Labs). Interestingly, there was no statistically significant difference between the exercised and sedentary animals in tumor doubling time (Fig. 5a). This doubling time was indistinguishable from the wild-type sedentary group. Furthermore, in contrast to the wild-type

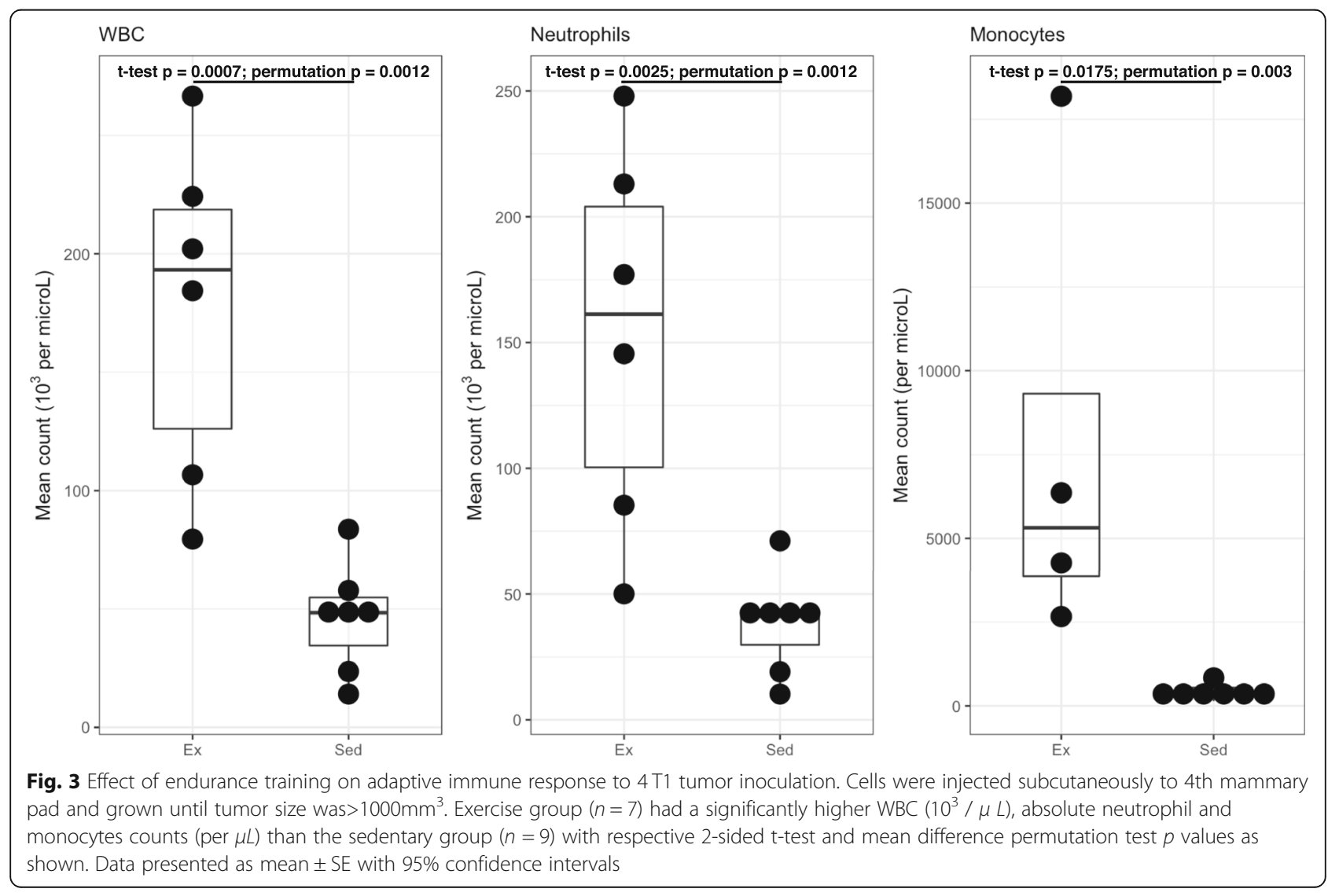




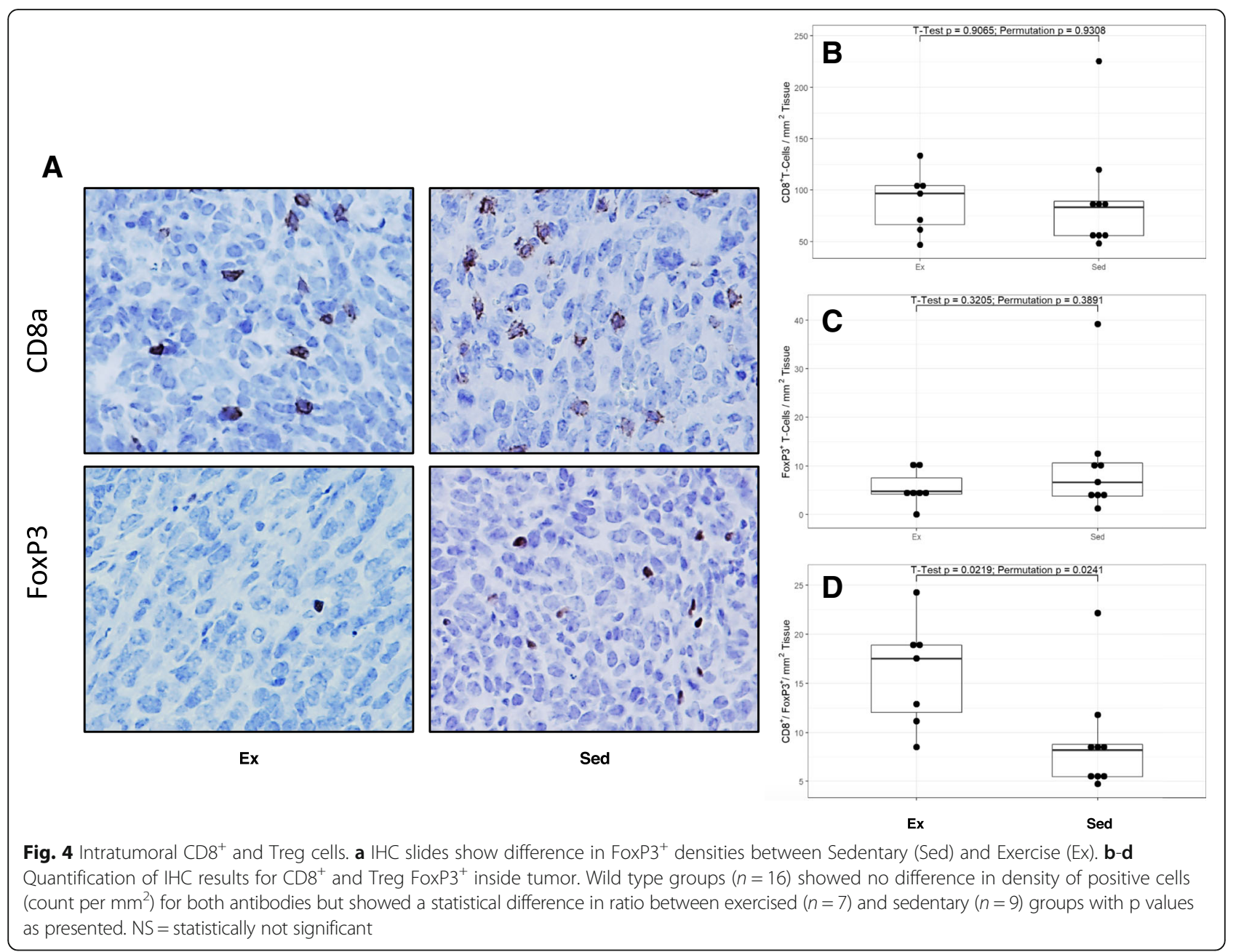

case mean tumor size in the exercised and sedentary athymic mice was never significantly different (Fig. 5b), and the Kaplan Meier survival curve showed no significant difference (Fig. 5c). Finally, no significant difference was detected in mean survival days after inoculation (23.875 days \pm 0.6 vs. $22.875 \pm 0.5$ ). Together this data suggests that exercise induced an enhanced antitumor immune response that suppressed tumor growth and ultimately enhanced animal survival.

\section{Discussion}

Physical activity has long been thought to mediate prevention of many chronic diseases. Many studies have indicated an association with exercise, physical activity, and/or fitness with tumor incidence, tumor growth, and cancer patient outcomes [32, 33]. Our model for endurance exercise training of murine animals showed a robust effect on the animals themselves but also a significant suppression of tumor growth, consistent with the findings of the studies mentioned above. Most interestingly, our data indicate that exercise promoted an enhanced antitumor immune response, evidenced by an increased $\mathrm{CD}^{+} / \mathrm{FoxP}^{+}$ratio in tumors. This effect of exercise training on the $T$ cell population within tumors has broad implications on the prevention and therapy of solid tumors and gives further evidence that physically fit patients are more likely to ward off chronic disease better than their sedentary counterparts.

The current study indicates an enhanced antitumor immune response in exercised mice but the molecular mechanism by which aerobic exercise could enhance immune function is less clear. Studies have suggested multiple mechanisms that could account for changes in immune function with exercise, such as increased myokines and cytokines secreted by active muscles [34] or an overexpression of adhesion molecules similar to febrile stress [35]. However, there are also other exerciseinduced physiological adaptations, and in particular adaptations to hypoxia, that could possibly play a role here, such as enhanced blood and oxygen delivery to tissues. 


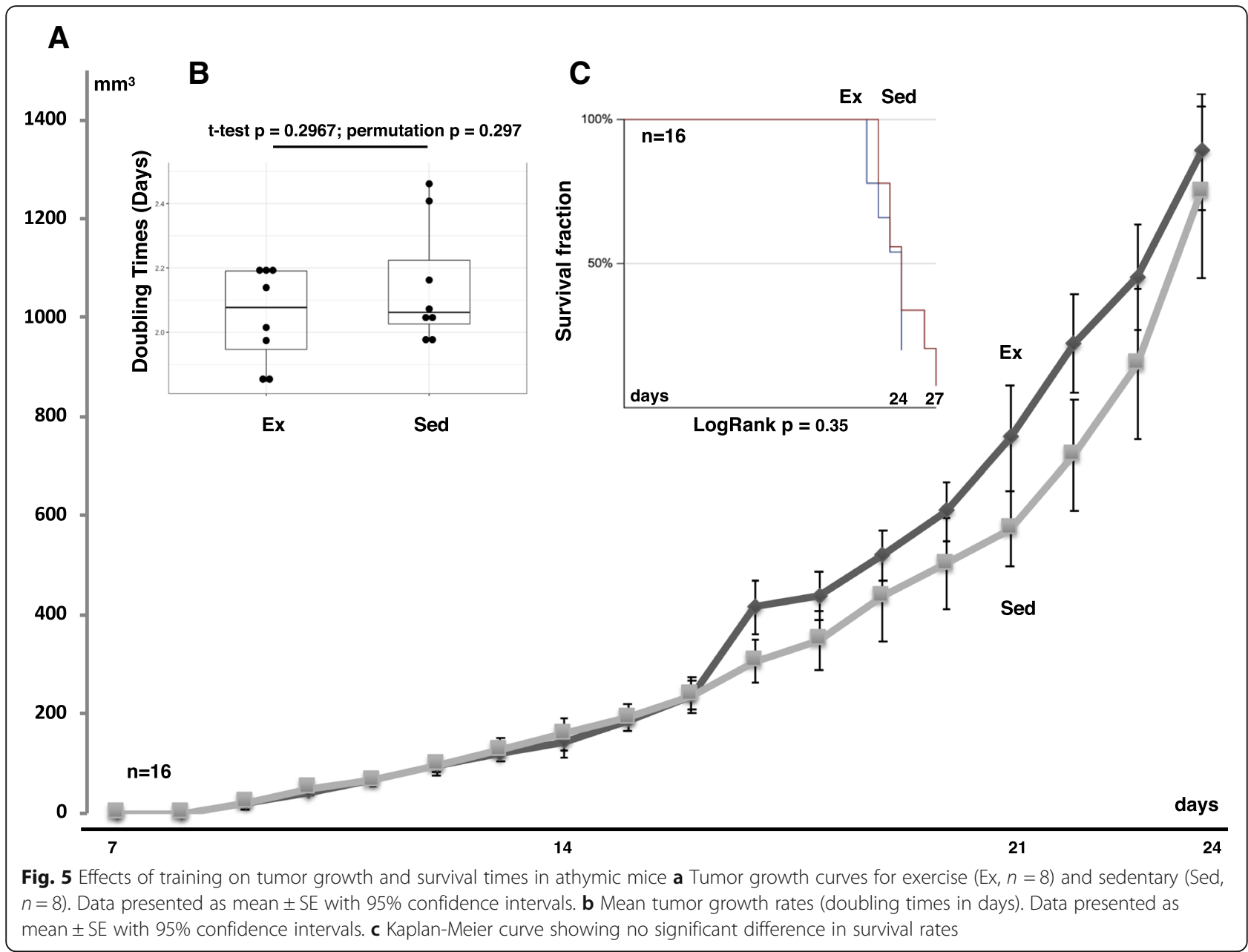

Enhanced blood delivery may possibly suppress a hypoxic response in tumors and lead to a faster degradation of HIF1 $\alpha$, a transcription factor which has been shown to upregulate molecules that attract FoxP3 ${ }^{+}$Treg cells $[36,37]$. Investigation is underway to determine molecular mechanisms driving the exercise-induced suppression of intratumoral FoxP3 ${ }^{+}$Tregs.

The development of our novel murine training method also fits an ideal model for testing and quantifying murine exercise. That aerobic exercise is qualitatively conducive to human health is widely accepted. A quantitative dose-response relationship between aerobic exercise and specific health conditions, while likely to exist, remains elusive. This gap in our understanding is due to unclear adherence, uncontrolled treatment fidelity, and the practical and ethical constraints on evaluating these in the critically ill. In order to probe the potential mechanistic pathways that underlie observed effects of endurance exercise on a range of health conditions, it is imperative to develop better exercise rodent models free from adverse and uncontrollable stress. An ideal model must also allow both the control and the quantification of the endurance exercise "dosage", so that a therapeutic spectrum of efficacy, a clinically effective dose, and predictors of response can be identified.

In the pilot study presented here we have shown that our new forced wheel running model is suitable to induce CEE in rodents without adverse stimuli. Furthermore, notwithstanding that the mice in our model ran significantly slower and less distance than mice in studies which were based on the voluntary wheel or the electric shock treadmill $[4,8,38,39]$, the lowest-commondenominator dosage we have achieved in continuous running after 8 weeks of training was sufficient to induce significant systemic changes in immune response before and after insult. In addition, the dosage "administered" via our exercise model and the training method described in this study are likely more relevant to human exercise routines than those murine exercise models with higher dosages. While exercise rodent models based on voluntary running (simulating HIIT) or electric shock treadmill (inducing CEE with adverse stimuli) are easy 
to implement (as they require no intervention from the experimenter), they seem inappropriate for achieving better understanding of the elusive dose-response relationship in exercise oncology. Healthy humans, let alone the critically ill, do not run intervals like mice on a voluntary wheel and are not forced to exercise after the point of exhaustion like mice on an electric shock treadmill. Specifically, non-athletes usually can perform HIIT only twice a week, and can do so (with appropriate careful warm-up and cool down interventions) only for 20$30 \mathrm{~min}$, while athletes may increase dosage to 3 times a week [40]. Thus, to truly simulate human-relevant dosage of HIIT, experimenters should block the voluntary wheel after 30 min and allow mice to run only 3 times a week. No such studies have been reported yet, but it is likely that in such conditions the total distance the mice ran would have been shorter and the effects observed would have been dampened. Finally, in contrast to the electric shock treadmill, our long and gentle training protocol got mice to run continuously and perform CEE without incurring stress. The point, however, is that not only such gentle protocol resulted in a more humanrelevant dosage, but it was also sufficient to induce the changes we observed.

Finally, the problem of translating murine exercise to human exercise is pertinent to all exercise oncology studies, and we haven't solved it here. We do believe, however, that our controllable and quantifiable exercise model has a better chance of making progress towards the desired solution. Work is underway to achieve this goal.

\section{Conclusion}

In the present study we have established a controllable and quantifiable rodent model for chronic endurance exercise, developed a low stress, conservative - yet efficacious - training protocol for it, and identified a potential cellular mechanism behind its effect on solid tumor progression. This cellular effect, the suppression of FoxP3 ${ }^{+}$ Treg cells recruitment into the tumor, is a novel finding and strongly implicates enhanced antitumor immunity as a means by which aerobic exercise can suppress tumor growth. Furthermore, this result indicates being endurance-trained (i.e. aerobically fit) could increase the likelihood for better patient outcomes and adds to the ever-growing list of reasons for engaging in regular aerobic activity.

\section{Additional file}

Additional file 1: Figure S1. Chronic endurance exercise model. Figure S2. Running protocol. Figure S3. Effect of endurance training on mtDNA copy number in muscle and liver. Figure S4. Wild-type animal weight and food intake. Figure S5. Effect of endurance training on circulating leukocytes. Figure S6. Antitumor immune response in exercised vs. sedentary wild type mice. (PDF $20084 \mathrm{~kb}$ )

\section{Abbreviations}

CBC: Cell Blood Count; CEE: Chronic Endurance Exercise; Ex: Exercised; HIIT: High Intensity Interval Training; IHC: Immunohistochemistry;

SE: Standard Error; Sed: Sedentary

\section{Acknowledgements}

We thank the three referees for their comments and suggestions, Stephanie Dickinson from IU SPH Biostatistics who helped in the statistical analysis of the revised version of the manuscript, and Meera Alderson, now a student at UNC, for her help in the lactate kinetics test and the mice training.

\section{Authors' contributions}

AH Conceptualization, animals handling, data analysis, data interpretation, manuscript writing. SK Animals handling, CEE wheel design, sample collection. ZW Cells injection, blood draw, sample collection, tissue analysis, data interpretation. JAS Animals handling and training, training protocol design, sample collection. LM Animals handling and training, training protocol design, sample collection, tissue analysis. SV Tissue analysis. RC Cells injection, sample collection, tissue analysis, data interpretation. JF Sample collection, tissue analysis, data interpretation. ZW, RC and JF Manuscript editing. All authors have read and approved the manuscript in its original and revised version.

\section{Funding}

AH acknowledges funding from the Indiana University Office of the Vice Provost for Research under the FRSP Seed Award program. IU OVPR had no role in the design of the study, the collection, analysis, and interpretation of data, and in the writing of the manuscript

\section{Availability of data and materials}

The datasets used and/or analyzed during the current study are available from the corresponding author on reasonable request.

\section{Ethics approval}

The study conformed to the standards and guidelines of Indiana University's humane animal care and was approved by the Indiana University Bloomington IACUC (protocol 16-013).

\section{Consent for publication}

Not Applicable.

\section{Competing interests}

The authors declare no conflict of interest.

\section{Author details}

${ }^{1}$ History \& Philosophy of Science \& Medicine Department, Indiana University, Morrison Hall 314, Bloomington, IN 47405, USA. ${ }^{2}$ Intelligent Systems Engineering Department, Indiana University, Bloomington, IN, USA. ${ }^{3}$ Environmental Health Department, School of Public Health, Indiana University, Bloomington, IN, USA. ${ }^{4}$ Medical Sciences Program, Indiana University School of Medicine, Bloomington, USA. ${ }^{5}$ Indiana University Cancer Center Indiana University School of Medicine, Indianapolis, USA. ${ }^{6}$ Department of Dermatology, Indiana University School of Medicine, Indianapolis, USA.

Received: 3 August 2018 Accepted: 23 May 2019

Published online: 04 June 2019

\section{References}

1. Hawley JA, Hargreaves M, Joyner MJ, Zierath JR. Integrative biology of exercise. Cell Metab. 2014;159:738-49.

2. Warburton DE, Nicol CW, Bredin SS. Health benefits of physical activity: the evidence. CMAJ. 2006;174:801-9.

3. Goh J, Ladiges W. Voluntary wheel running in mice. Current protocols in mouse biology. 2015;5(4):283-90.

4. Marcaletti S, Thomas C, Feige JN. Exercise performance tests in mice. In: Current protocols in mouse biology, vol. 1; 2011. p. 141-54. 
5. Legerlotz K, Elliott B, Guillemin B, Smith HK. Voluntary resistance running wheel activity pattern and skeletal muscle growth in rats. Exp Physiol. 2008; 93(6):754-62.

6. Milanovic Z, Sporis G, Weston M. Effectiveness of high-intensity interval training (HIT) and continuous endurance training for $\mathrm{VO}_{2 \mathrm{Max}}$ improvements: a systematic review and meta-analysis of controlled trials. Sports Med. 2015; 45:1469-81.

7. Foster C, Farland CV, Guidotti F, Harbin M, Roberts B, Schuette J, et al. The effects of high intensity interval training vs. steady state training on aerobic and anaerobic capacity. J Sports Sci Med. 2015;14:747-55.

8. Chen CC, Chang MW, Chang CP, Chan SC, Chang WY, Yang CL, et al. A forced running wheel system with a microcontroller that provides highintensity exercise training in an animal ischemic stroke model. Braz J Med Biol Res. 2014;47(10):858-68.

9. Friedenreich $\mathrm{CM}$, et al. Physical activity and cancer outcomes: a precision medicine approach. Clinical Cancer Approach. 2016;22(19):4766-75.

10. Monninkhof EM, Elias SG, Vlems FA, et al. Physical activity and breast cancer: a systematic review. Epidemiol. 2007;18:137-57.

11. Hagar A, Flynn S, Patterson K, Haddad F. Muscular endurance and progression rates of early stage invasive ductal carcinoma - a pilot study. Breast J. 2018;24(5):849-51.

12. Pedersen BK, Hoffman Goetz L. Exercise and the immune system: regulation, integration, and adaptation. Physiol Rev. 2000;80(3):1056-81.

13. Decker WK, da Silva RF, Sanabria MH, Angelo LS, Guimarães F, Burt BM, et al. Cancer immunotherapy: historical perspective of a clinical revolution and emerging preclinical animal models. Front Immunol. 2017;8:829.

14. Tang J, Shalabi A, Hubbard-Lucey VM. Comprehensive analysis of the clinical immuno-oncology landscape. Ann Oncol. 2018;29:84-91.

15. Berendt MJ, North RJ. T-cell-mediated suppression of anti-tumor immunity JEM. 1980;151(1):69-80

16. Shimizu J, Yamazaki S, Sakaguchi S. Induction of tumor immunity by removing CD25+CD4+ T cells: a common basis between tumor immunity and autoimmunity. J Immunol. 1999;163:5211-8.

17. Chaudary B, Elkord E. Regulatory T cells in the tumor microenvironment and cancer progression: role and therapeutic targeting. Vaccines. 2016;4(3):28.

18. Facciabene A, Motz GT, Coukos G. T regulatory cells: key players in tumor immune escape and angiogenesis. Cancer Res. 2012;72(9):2162-71.

19. Yan M, Jene N, Byrne D, Millar EK, OToole SA, McNeil CM, et al. Recruitment of regulatory $T$ cells is correlated with hypoxia-induced CXCR4 expression and is associated with poor prognosis in basal-like breast cancers. Breast Cancer Res. 2011;13:R47.

20. Shang B, Liu Y, Jiang S, Liu Y. Prognostic value of tumor-infiltrating FoxP3 ${ }^{+}$regulatory $T$ cells in cancers: a systematic review and meta-analysis. Sci Rep. 2015;5:15179.

21. Carpenter RL, Paw I, Dewhirst MW, Lo HW. Akt phosphorylates and activates HSF-1 independent of heat shock, leading to slug overexpression and epithelial-mesenchymal transition (EMT) of HER2-overexpressing breast cancer cells. Oncogene. 2015;34(5):546-57.

22. Carpenter RL, Sirkisoon S, Zhu D, Rimkus T, Harrison A, Anderson A, et al. Combined inhibition of AKT and HSF1 suppresses breast cancer stem cells and tumor growth. Oncotarget. 2017:8(43):73947-63.

23. Fitzsimons DP, Diffee GM, Herrick RE, Baldwin KM. Effects of endurance exercise on isomyosin patterns in fast- and slow-twitch skeletal muscles. J Appl Physiol. 1990;68(5):1950-5.

24. Sheng JJ, Jin JP. TNNI1 TNNI2 and TNNI3: evolution, regulation, and protein structure-function relationships. Gene. 2015;576(1 Pt 3):385-94.

25. Cao X, Zhao ZW, Zhou HY, Chen GQ, Yang HJ. Effects of exercise intensity on copy number and mutations of mitochondrial DNA in gastrocnemus muscles in mice. Mol Med Rep. 2012;6:426-8.

26. Lezi E, Lu J, Burns JM, Swerdlow RH. Effect of exercise on mouse liver and brain bioenergetic infrastructures. Exp Physiol. 2013;98(1):207-19.

27. Lee HC, Wei YH. Mitochondrial biogenesis and mitochondrial DNA maintenance of mammalian cells under oxidative stress. Int J Biochem Cell Biol. 2005:37:822-34

28. Goodwin ML, Harris JE, Hernandez A, Gladden B. Blood lactate measurements and analysis during exercise, a guide to clinicians. J Diab Sci \& Tech. 2007;1 (4):558-69

29. Dugger KJ, Chrisman T, Sayner SL, Chastain P, Watson K, Estes R. Beta-2 adrenergic receptors increase TREG cell suppression in an OVA-induced allergic asthma mouse model when mice are moderate aerobically exercised. BMC Immunol. 2018;19:9-22.
30. Horn PL, Pyne DB, Hopkins WG, Barnes CJ. Lower white blood cell counts in elite athletes training for highly aerobic sports. Eur J Appl Physiol. 2010; 110(5):925-32.

31. Thomas RJ, Kenfield SA, Jimenez A. Exercise-induced biochemical changes and their potential influence on cancer: a scientific review. Br J Sports Med. 2017;51:640-4

32. Moore SC, Lee IM, Weiderpass E, Campbell PT, Sampson JN, Kitahara CM, et al. Association of leisure-time physical activity with risk of 26 types of cancer in 1.44 million adults. JAMA Intern Med. 2016:176(6):816-25.

33. Friedenreich CM. The role of physical activity in breast Cancer etiology. Semin Oncol. 2016:37(3):297-302

34. Pedersen L, Idorn M, Olofsson GH, Lauenborg B, Nookaew I, Hansen RH, et al. Voluntary running suppresses tumor growth through epinephrine- and IL-6-dependent NK cell mobilization and redistribution. Cell Metab. 2016;23: 554-62.

35. Evans SS, Repasky EA, Fisher DT. Fever and the thermal regulation of immunity: the immune system feels the heat. Nat Rev Immunol. 2015;15(6): $335-49$

36. Ren L, Yu Y, Wang L, Zhu Z, Lu R, Yao Z. Hypoxia-induced CCL28 promotes recruitment of regulatory $T$ cells and tumor growth in liver cancer. Oncotarget. 2016;7(46):75763-73.

37. Facciabene A, Peng X, Hagemann IS, Balint K, Barchetti A, Wang LP, et al. Tumour hypoxia promotes tolerance and angiogenesis via CCL28 and Treg cells. Nature. 2011:475:226-31.

38. Svensson M, Rosvall P, Boza-Serrano A, Andersson E, Lexell J, Deierborg T. Forced treadmill exercise can induce stress and increase neuronal damage in a mouse model of global cerebral ischemia. Neurobiology of Stress. 2016; 5:8-18.

39. Meijer JH, Robbers Y. Wheel running in the wild. Proc R Soc B. 2014;281: 20140210.

40. Karlsen T, Aamot I, Haykowsky M, Rognmo O. High intensity interval training for maximizing health outcomes. Prog Cardiovasc Dis. 2017;60:10.1016.

\section{Publisher's Note}

Springer Nature remains neutral with regard to jurisdictional claims in published maps and institutional affiliations.

Ready to submit your research? Choose BMC and benefit from:

- fast, convenient online submission

- thorough peer review by experienced researchers in your field

- rapid publication on acceptance

- support for research data, including large and complex data types

- gold Open Access which fosters wider collaboration and increased citations

- maximum visibility for your research: over $100 \mathrm{M}$ website views per year

At $\mathrm{BMC}$, research is always in progress.

Learn more biomedcentral.com/submissions 